\title{
Control of multiple VSC-HVDC converters within an offshore AC-hub
}

\author{
Jonathan Stevens, Student Member, IEEE, Daniel Rogers, Member, IEEE, \\ Institute of Energy \\ Cardiff University \\ Cardiff, UK
}

\begin{abstract}
The offshore node will be a key component of a future European Supergrid. The offshore AC hub (or SuperNode) is presented as one possible topology of an offshore node. Tranche $A$ is an area within Dogger Bank, which is one of the UK's largest offshore wind development zones. It is a likely location of an offshore AC hub and therefore is used as a case study. Two strategies are presented for control of voltage, current and power within the offshore AC hub. The performance of each control strategy is compared under both planned and unplanned changes in operating conditions. Simulations are carried out using the SimPower toolbox of MATLAB Simulink. It is found that both control strategies are able to maintain satisfactory control of voltage, current and power. The communication requirements of each strategy are also briefly discussed.
\end{abstract}

Index Terms-Flexible AC transmission systems, HVDC transmission, Power system control.

\section{INTRODUCTION}

In response to the challenges presented by global warming, the depletion of fossil fuel reserves and concerns over security of supply following the integration of increasing amounts of intermittent renewable energy resources, there is widespread support within Europe for the development of a pan-European Supergrid [1-4]. A Supergrid will facilitate the integration of large offshore renewable energy projects, often located in remote locations. It will enable spatial smoothing through aggregation of resources, reducing the variability of the renewable energy sources. For example, interconnection with Scandinavia will provide access to hydro energy storage facilities. It overcomes many of the issues associated with installing new overhead lines or underground cables in onshore networks; effectively a bypass is provided thus reducing congestion of power flows from energy source to load center. It will increase the security of supply through reduced dependency on gas and oil from unstable regions. Finally, it will improve trade and competition in energy markets through provision of more interconnections between countries, resulting in increased possibilities for arbitrage and limitation of price spikes [2], [3].

A key element of a Supergrid is the offshore node or hub, which provides a common connection point for a number of offshore wind farms and allows for interconnection between countries. Multi-terminal HVDC technology is one prominent technical solution for the formation of an offshore node or hub. An alternative solution for the offshore node or hub is the "SuperNode concept" as presented in [4]. A SuperNode is an

Work supported by the EPSRC UK Industrial Case Award Program (Grant No. 11220744) with sponsorship from Ove Arup and Partners Ltd. offshore network which provides interconnection between adjacent converters via an AC-hub arrangement. A key question is how voltage, current and power can be managed within this AC-hub arrangement.

If it is assumed that Fully Rated Converter Wind Turbines (FRC-WT) make up the generation within the SuperNode and the connection to shore is made via VSC-HVDC converters, then a key characteristic of an offshore $\mathrm{AC}$ hub is realized; it is an islanded network connected exclusively by converters. Additionally, unlike traditional onshore AC networks, there are no rotating machines directly connected to the network and hence there is no physical inertia. In fact, the only significant energy storage present within the network of the offshore node is provided by the DC capacitors of the VSCHVDC links and FRC-WTs [5].

Similar characteristics have been previously described in the literature relating to autonomous islanded low-voltage distribution networks or microgrids [6-8]. However, one key difference between them is the presence of a large amount of cable capacitance within the offshore AC hub. Two prominent control strategies identified within the literature include a master-slave control approach and a droop control approach. In the master-slave control strategy, a master controller is defined which manages voltage and frequency within the network and a slave controller is defined which controls complex power. In the droop control scheme, each participating converter executes control of voltage and frequency and hence shares the real and reactive power transfer. This paper will evaluate the suitability of both control strategies for application within an offshore AC-hub.

\section{CASE STUDY - DOGGER BANK}

The UK Crown Estate Round 3 zone known as Dogger Bank has been identified as a possible location of an offshore AC hub. This is because a large amount of wind generation is expected to be built there; hence aggregation of wind energy is required. Also, assuming an interconnection between Norway and the UK is to be built, it may be more viable to route the interconnection via Dogger Bank, thus utilizing previously installed assets and avoiding difficulties associated with locating onshore converter stations. Near-term development within the Dogger Bank zone is planned to take place within Tranche A in the form of three projects. Each project is expected to include up to $1200 \mathrm{MW}$ of wind generation [9]. 


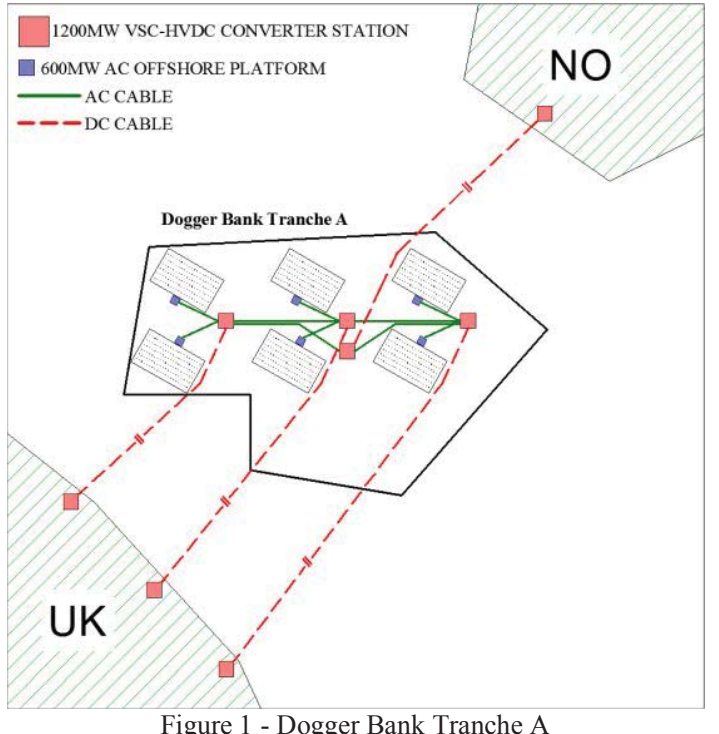

Fig. 1 describes the infrastructure development within Tranche A assumed within this paper. Each project uses a single point-to-point (P2P) VSC-HVDC link with a rating of 1200MVA. A fourth P2P VSC-HVDC link, also with a rating of 1200MVA is included to provide interconnection between the UK and Norway. Each offshore VSC-HVDC converter station is connected via $\mathrm{AC}$ cables thus forming the offshore AC hub.

\section{MODELLING OF AN OFFSHORE AC-HUB}

A model of the offshore $\mathrm{AC}$ hub has been developed within the SimPower systems toolbox of MATLAB Simulink. The components are modeled in the natural $(a b c)$ reference frame. Fig. 4 presents the single line diagram of the model. Fig. 2 presents the offshore converter of each HVDC P2P link which is represented by an ideal voltage source behind an impedance network representative of the convertor reactor and transformer impedance. Each HVDC link is assumed to have a capacity of $1200 \mathrm{MVA}$, where $V_{D C}= \pm 320 \mathrm{kV}, V_{A C}=$ $400 \mathrm{kV}$. The converter transformer steps down the voltage from $400 \mathrm{kV}$ to $220 \mathrm{kV}$. Assuming the converter is of a modular multi-level (MML) topology, AC filters are not normally required as there is minimal harmonic content produced in the conversion process [10]. The switching dynamics are also neglected.

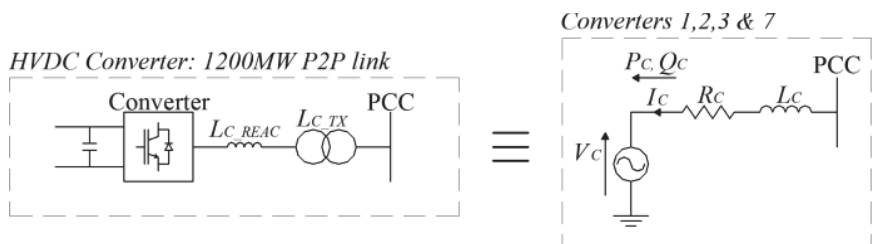

Figure 2 - Model of a HVDC-VSC $\overline{\mathrm{P}} \overline{\mathrm{P}}$ link

Each FRC-WT has a capacity of 5MVA. 120 FRC-WTs are connected to a single $600 \mathrm{MVA}$ AC substation at $33 \mathrm{kV}$. The wind array (WA) substation steps up the voltage to $220 \mathrm{kV}$ for transmission to the HVDC links. As presented in Fig. 3, two WAs are assumed in parallel and represented by an ideal voltage source behind an impedance network representative of the aggregated FRC reactor, transformer impedance and WA transformer impedance.

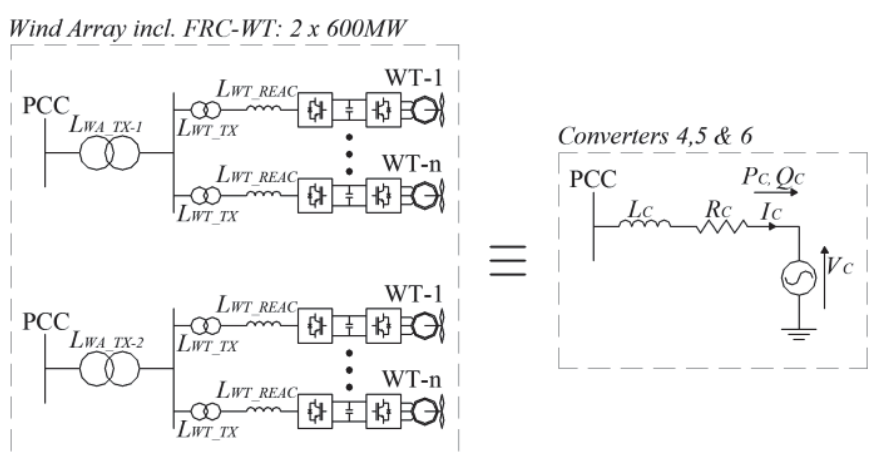

Figure 3 - Aggregated model of a WA

The AC cables are modeled by an equivalent $\Pi$-network, thus ensuring the capacitive nature of the cables is captured.

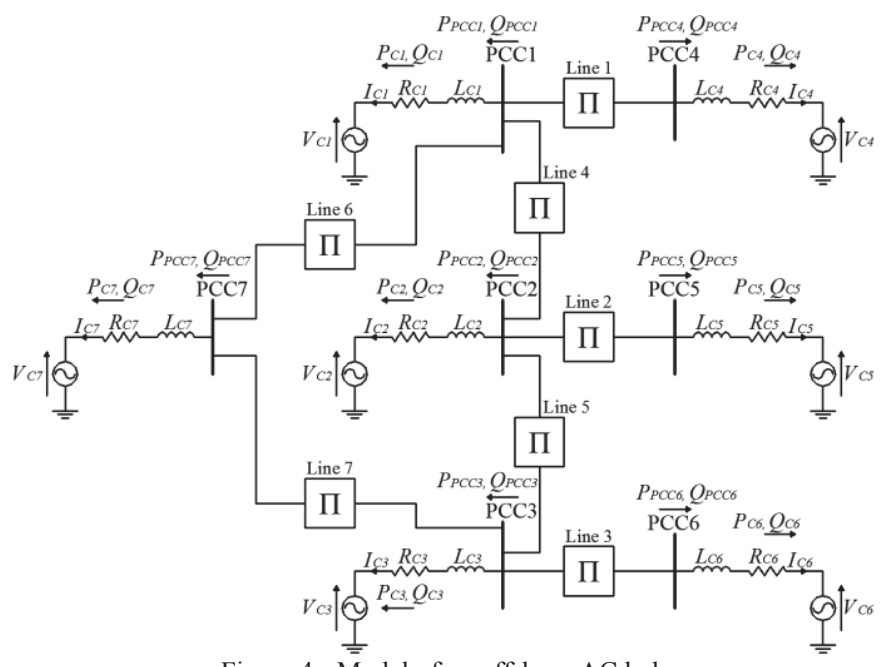

Figure 4 - Model of an offshore AC hub

\section{A. The Master-Slave control strategy}

Within the master-slave control strategy, HVDC converter 1 , the master converter, maintains the voltage at $V_{P C C 1}$ to the voltage reference $V_{P C C 1}^{*}$ and sets the frequency of the network $\omega$ to the nominal frequency $\omega_{N}$. As the voltage magnitude and angle are held constant at PCC1 it can be described as the slack bus within the system, generating or absorbing complex power as necessary. HVDC converters 2, 3 and 7 are defined as slave converters. Their role is to maintain the complex power generated or absorbed at the connected PCC to the scheduled values $P_{P C C n}^{*}, Q_{P C C n}^{*}$. Each slave converter uses a Phase Locked Loop (PLL) to lock on to the voltage waveform produced by the master converter. Fig. 5 presents the control structure used within the master and slave converters. A dual loop vector control scheme is employed in the synchronous $(d q)$ reference frame using PI controllers [11]. The inner current control loop is universally applied to all converters. For the master converter, the outer loop provides the current reference for the inner loop through controlling $V_{P C C 1}$. For the slave converter, the outer loop provides the current reference for the inner loop through controlling $P_{P C C n}, Q_{P C C n}$. 

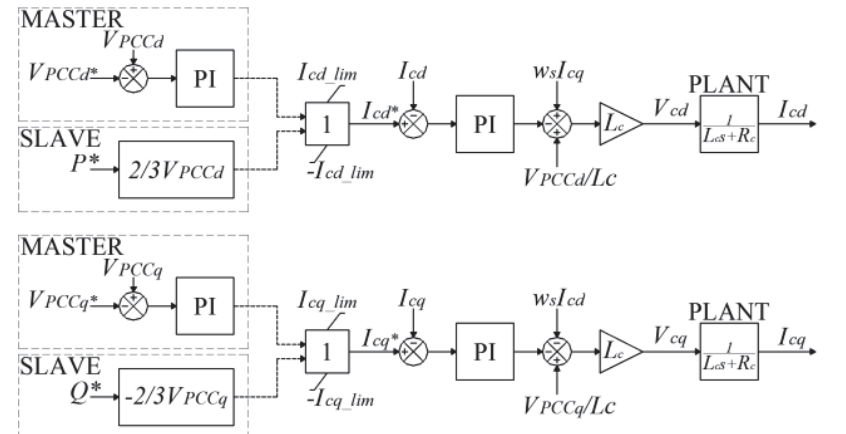

Figure 5 - Converter Control Loops

FRC-WT converters 4,5 and 6 are expected to output as much active power as is available from the wind. This is usually achieved by exporting active power as necessary to maintain a constant voltage across the FRC-WT DC link [12]. Within this study, the DC dynamics have been neglected. In addition, if possible the FRC-WT is required to participate in reactive compensation of the offshore AC network. The control strategy utilized for the slave converter was adopted in order to allow complex power input to the network to be simulated.

\section{B. The Droop control strategy}

Within the droop control strategy, HVDC converters 1, 2 and 3 all participate in maintaining voltage and frequency within the network. This implies that complex power is automatically shared amongst the three converters. Each droop converter utilizes the same dual-loop control scheme as defined for the master converter within the master-slave control scheme. However, rather than $\omega$ being fixed at $\omega_{n}$, it is drooped against $P_{P C C n}$ according to the droop gain $m_{p}$ as given in (1) [6].

$$
\omega=\omega_{n}-m_{p} P_{P C C n}
$$

In addition, rather than $V_{P C C d}^{*}$ being fixed at the nominal voltage $V_{n}$, it is drooped against $Q_{P C C n}$ according to the droop gain $n_{q}$ as given in (2) [6].

$$
V_{P C C d}^{*}=V_{n}-n_{q} Q_{P C C n}
$$

The droop gains are specified as given in (3) and (4).

$$
\begin{gathered}
m_{p}=\frac{\omega_{\max }-\omega_{\min }}{P_{\max }} \\
n_{q}=\frac{V_{c d(\max )}-V_{c d(\min )}}{Q_{\max }}
\end{gathered}
$$

Converters 4, 5, 6 and 7 are assumed to control complex power as defined by $P_{P C C n}^{*}, Q_{P C C n}^{*}$. Therefore, these converters utilize the same dual loop control scheme as defined for the slave converter within the master-slave control scheme.

\section{SimUlation}

\section{A. Operating Scenarios}

In order to compare both the master-slave and droop control strategy, two simulation cases have been developed. Each case begins with the same initial operating condition. All converters (VSC-HVDC and FRC-WT) are expected to provide reactive compensation where possible. Therefore, it is necessary to optimize active and reactive power flow within the network. Network optimization is an involved procedure and at present is outside the scope of this work. However, a standardized procedure is followed to determine scheduled power orders for each case as described in Fig. 6. The cases are as follows:

Initial State: Wind generation is at $75 \%$ of rated. WT converters 4, 5 and 6 provide an amount of reactive compensation in order to maximize active power transfer through HVDC converters 1, 2, 3 \& 7. Electricity prices in Norway are cheaper than in the UK; therefore, the direction of energy transfer is to the UK from Norway. Maximum permissible active power is absorbed at PCC 1,2 and 3 and injected at PCC 7 accordingly.

Case 1 - Planned change in operating conditions: Wind generation is at $75 \%$ of rated. Electricity prices in UK become cheaper than in the Norway. This is simulated by a change in active power at PCC 7 from generating to absorbing. Power flow is re-allocated amongst the remaining converters. All set points change according to a two second ramp.

Case 2 - Unplanned change in operating conditions: Wind generation is at $75 \%$ of rated. A fault is assumed on the onshore AC network which requires HVDC converter 3 to rapidly reduce active power transfer to zero. A step change in active current reference is simulated to block active current flowing through the converter. Power flow is re-allocated amongst the remaining converters.

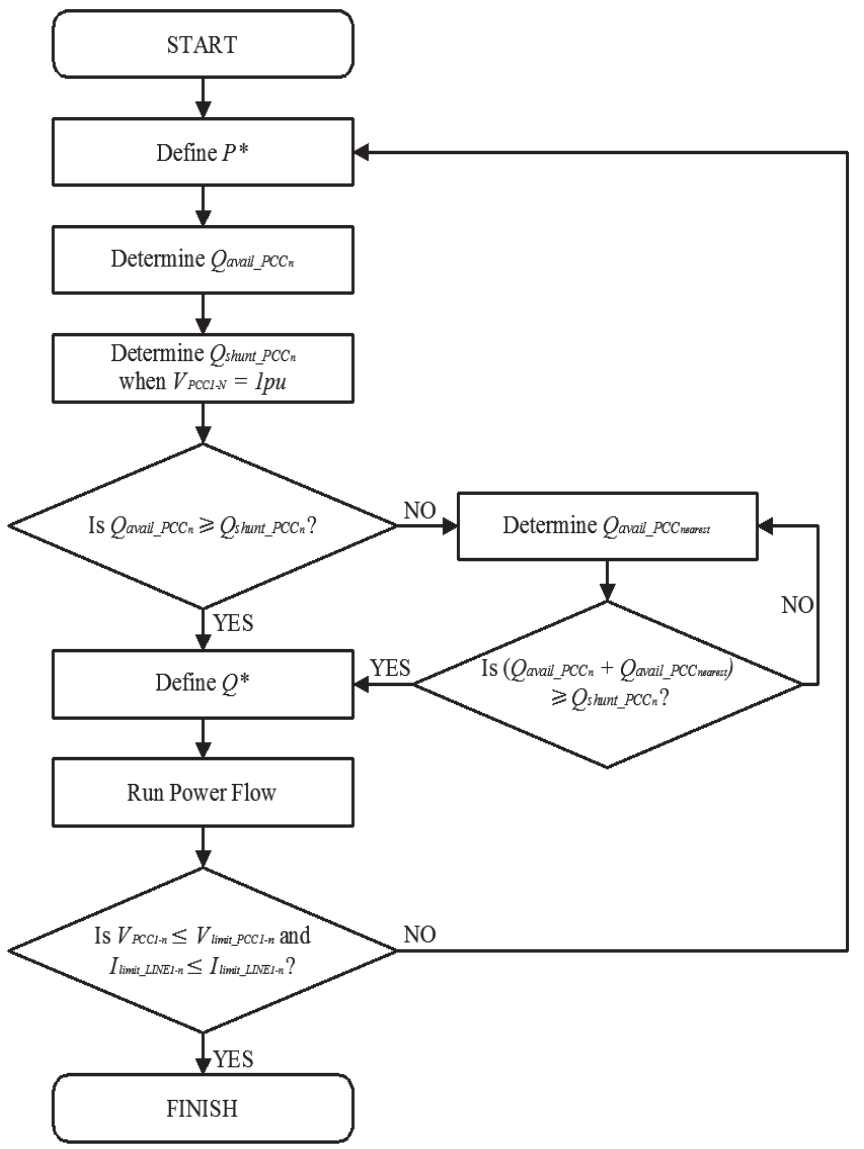

Figure 6 - Defining scheduled active and reactive power transfer 


\section{B. Results and discussion}

Each case is simulated twice, once using the master-slave control strategy and once using the droop control strategy. Note that the start-up process is not discussed in this paper.

Case 1 - Planned change in operating conditions (Fig. $7 \&$ 8): At $t=1 \mathrm{~s}$, a ramp change in scheduled power orders begins, with the final state being achieved at $t=3 \mathrm{~s}$. Fig. 7a shows the voltage magnitude $\left(\left|V_{P C C_{1-7}}\right|\right)$ at each PCC when using the master-slave control strategy. The voltages across all PCCs are almost equal. This is expected due to the relatively small series impedance of the lines. The maximum voltage deviation $\triangle V_{P C C}$ from the nominal voltage during the state transition is $0.025 \mathrm{pu}$. Therefore, clearly the master converter (HVDC converter 1) is able to maintain $\left|V_{P C C_{1-7}}\right|$ to within reasonable limits.
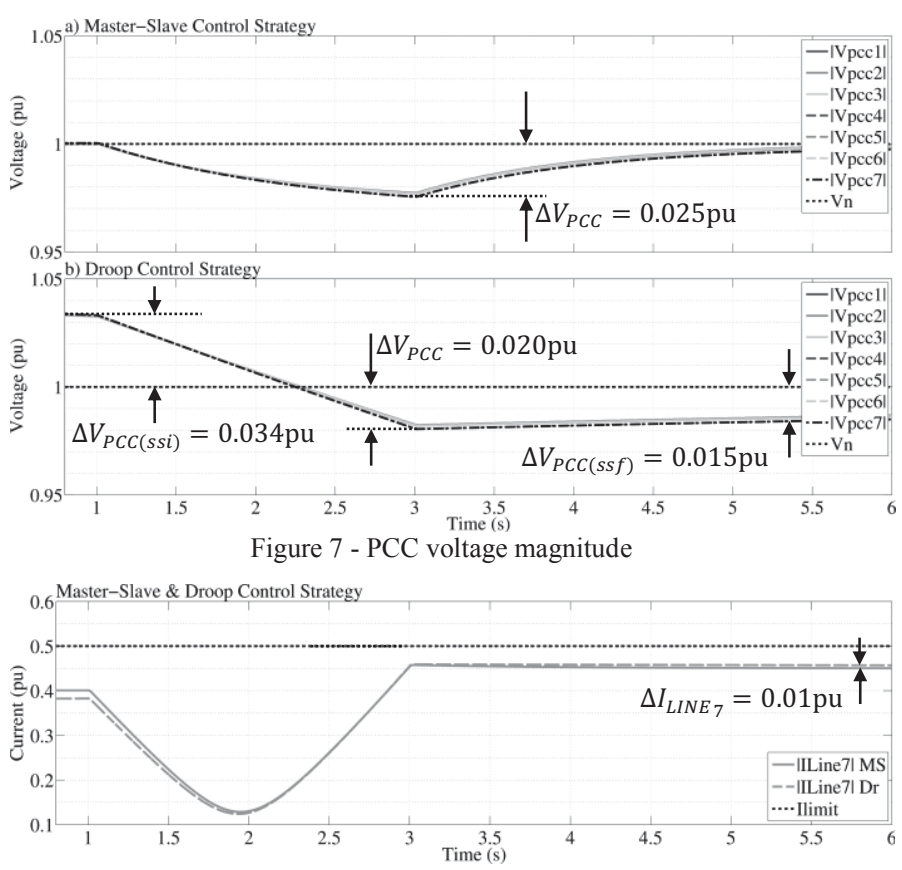

Figure 8 - Line 7 current magnitude

Fig. 7b shows $\left|V_{P C C_{1-7}}\right|$ when using the droop control strategy. The maximum voltage deviation $\triangle V_{P C C}$ from the nominal voltage during the state transition is $0.020 \mathrm{pu}$. The droop converters (HVDC converters 1, 2 \& 3) are able to maintain $\left|V_{P C C_{1-7}}\right|$ within reasonable limits. However, the initial $\left(\triangle V_{P C C(S S i)}\right)$ and final $\left(\triangle V_{P C C(s s f)}\right)$ steady state voltages are offset from the nominal voltage. This is due to the V/Q droop. A similar offset is observed with $\omega$. The effect of this droop is to increase the current throughout the network for the same power transfer. As a result, the current through line 7 is greater when using the droop control strategy. While this difference is marginal, it will of course incur greater line losses. Supplementary control is one technique used to overcome this issue [13], [14]. The supplementary control action raises or lowers $\omega_{n}$ and $V_{n}$ of equations 1 and 3 respectively, thus adjusting the voltage and frequency reference. This would require some form of communication with only a relatively low bandwidth and is not latency sensitive.
Case 2 - Unplanned change in operating conditions (Fig. 9 \& 10): At $t=1 \mathrm{~s}$, a step change in the active current reference $\left(I_{C d_{3}}^{*}\right)$ occurs, simulating an emergency reduction of active power flow through HVDC converter 3 . In response, action must be taken to address the power imbalance within the network. After a small calculation and communication delay (simulated as $100 \mathrm{~ms}$ ), at $t=1.1 \mathrm{~s} P_{P C C_{7}}^{*}$ steps to zero to stop the import of active power from Norway. Additionally, $P_{P C C_{4-6}}^{*}$ step to a reduced value, simulating shut down of some of the FRC-WTs. It is assumed that sufficient communication bandwidth is available to re-allocate power orders in this short time scale and that latency is low.
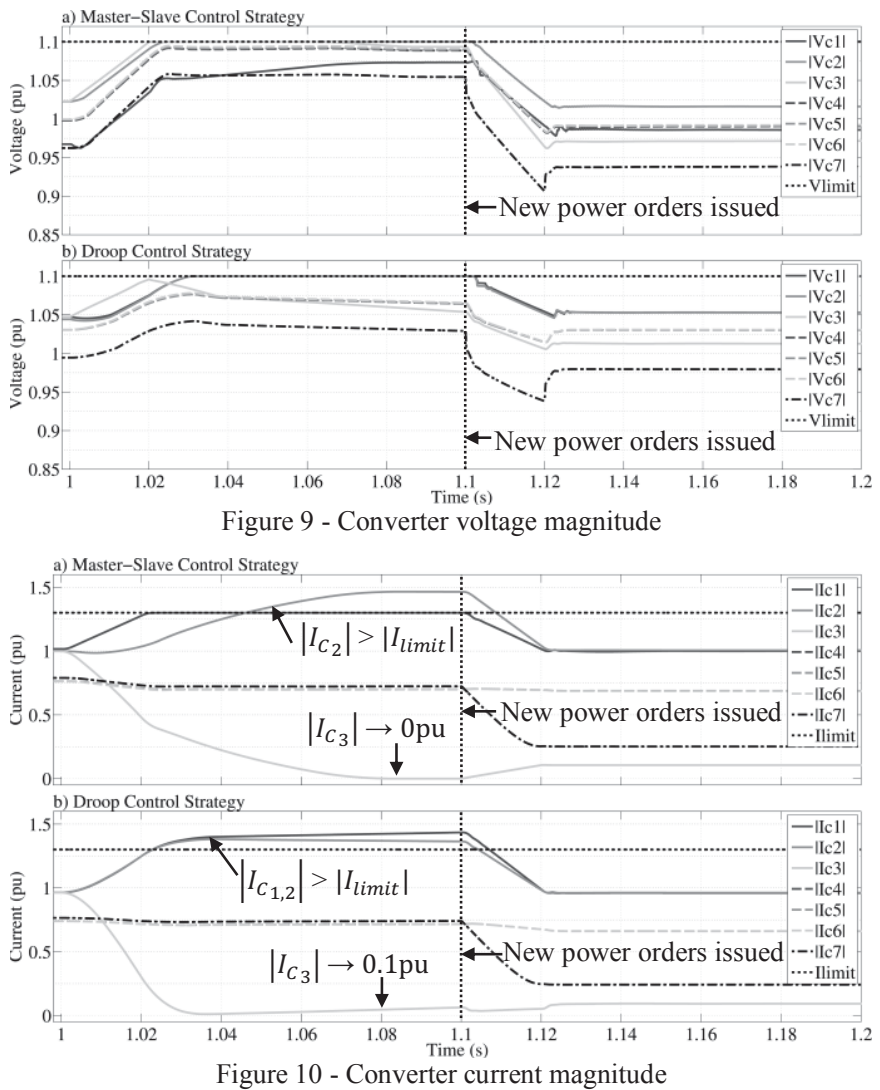

Fig. 9a and 10a show the voltage $\left(\left|V_{C_{1-7}}\right|\right)$ and current $\left(\left|I_{C_{1-7}}\right|\right)$ magnitude across each converter respectively, when using the master-slave control strategy. After $20 \mathrm{~ms}$, the voltage limit of HVDC converter 3 is reached as the current controller attempts to reduce $\left|I_{C_{3}}\right|$ to zero. The reduction in $\left|I_{C_{3}}\right|$ causes an increase in $\left|V_{P C C_{1-7}}\right|$. The master converter responds by increasing $\left|I_{C_{1}}\right|$, as it tries to maintain $\left|V_{P C C_{1}}\right|$. After $25 \mathrm{~ms}$, the master converter reaches the current limit. As $\left|I_{C_{3}}\right|$ continues to reduce to zero, $\left|I_{C_{2}}\right|$ increases and exceeds the current limit. HVDC converter 2 absorbs the excess current. It is observed that $\left|I_{C_{2}}\right|$ only reduces as soon as new scheduled power orders are issued. Therefore, the masterslave control strategy requires fast reduction of power generation to ensure the overload through HVDC converter 2 is not sustained. 
Fig. 9b and 10b show the voltage $\left(\left|V_{C_{1-7}}\right|\right)$ and current $\left(\left|I_{C_{1-7}}\right|\right)$ magnitude across each converter respectively, when using the droop control strategy. Immediately after the step change in $I_{C d_{3}}^{*}$, the voltage angle of HVDC converter 3 reduces to limit the absorption of active power. $\left|I_{C_{3}}\right|$ reduces causing an increase in $\left|V_{P C C_{1-7}}\right|$. The droop converters respond by increasing $\left|I_{C_{1,2}}\right|$ as they try to maintain $\left|V_{P C C_{1,2}}\right|$. After $25 \mathrm{~ms}$, both droop converters reach the current limit. As $\left|I_{C_{3}}\right|$ continues to reduce to zero, $\left|I_{C_{1,2}}\right|$ increase and exceed the current limit. HVDC converters $1 \& 2$ absorb the excess current. $\left|I_{C_{3}}\right|$ stabilizes at approximately $0.1 \mathrm{pu}$. At this point, $\left|I_{C_{3}}\right|$ is reactive as $I_{C d_{3}}$ is zero. It is observed that $\left|I_{C_{1,2}}\right|$ only reduce as soon as new scheduled power orders are issued. Therefore the droop control strategy also requires fast reduction of power generation to ensure the overload through HVDC converters $1 \& 2$ is not sustained. Fast communication of new power orders in both strategies is seen to be effective in mitigating the power imbalance within the offshore $\mathrm{AC}$ hub. Other techniques have been developed in [11] \& [12] for a single P2P HVDC link and WA.

A summary of the control system response following planned and unplanned events is given in Fig. 11.

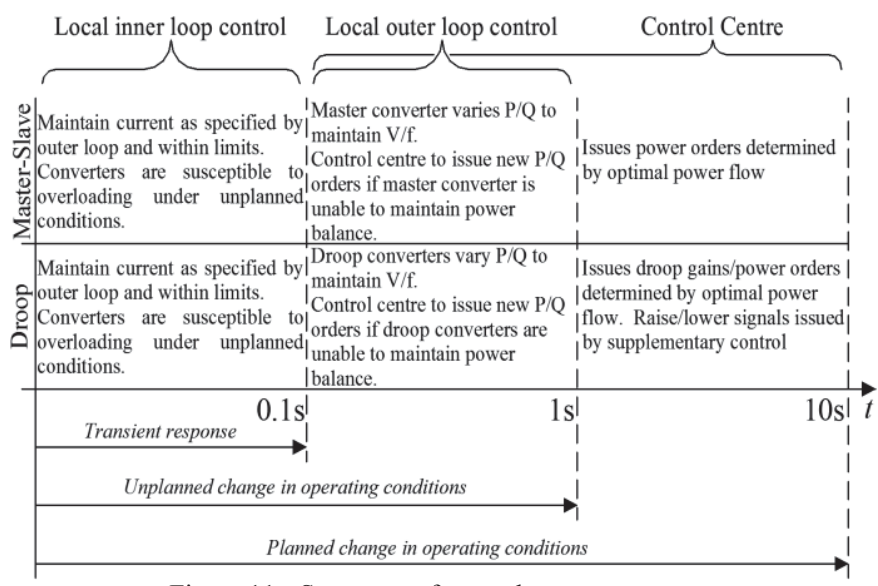

Figure 11 - Summary of control system response

\section{CONCLUSIONS}

Two control strategies have been evaluated for application within an offshore AC hub. The performance of each control strategy is tested during a planned change in operating conditions. Both control strategies are seen to maintain satisfactory control of voltage, current and power throughout the transition. It is shown that the droop control scheme can automatically share real and reactive power independently among three converters. However, the droop control strategy requires supplementary control in order to maintain nominal voltage and current. The performance of each control strategy is also tested during a significant unplanned event occurring within the network. Both control strategies are seen to operate as required however, fast communication of new complex power orders is required to manage the event in both cases. Work will progress with the implementation and evaluation of other control strategies in due course.

\section{ACKNOWLEDGMENT}

The authors gratefully acknowledge the support of K. Siriwardhana of Ove Arup and Partners Ltd.

\section{REFERENCES}

[1] The Energy and Climate Change Committee, "House of Commons Energy and Climate Change Committee A European Supergrid," 2011.

[2] EWEA, "Oceans of Opportunity," 2009.

[3] OffshoreGrid, "OffshoreGrid : Offshore Electricity Infrastructure in Europe Offshore Electricity," 2011.

[4] Friends of the Supergrid, "Position paper on the EC

Communication for a European Infrastructure Package," Brussels, 2010.

[5] T. K. Vrana, R. E. Torres-Olguin, B. Liu, and T. M. Haileselassie, "The North Sea super grid - a technical perspective," in 9th IET International Conference on AC and DC Power Transmission (ACDC 2010), 2010, pp. O65-O65.

[6] N. Pogaku, M. Prodanovic, and T. C. Green, "Inverter-based microgrids: small-signal modelling and testing," Power Electronics, Machines and Drives, 2006. PEMD 2006. The 3rd IET International Conference on, pp. 499-504.

[7] C. K. Sao and P. W. Lehn, "Control and Power Management of Converter Fed Microgrids," IEEE Transactions on Power Systems, vol. 23, no. 3, pp. 1088-1098, Aug. 2008.

[8] M. Prodanovic, "A survey of control methods for three-phase inverters in parallel connection," in 8th International Conference on Power Electronics and Variable Speed Drives, 2000, vol. 2000, pp. 472-477.

[9] Forewind, "Forewind - Zone development." [Online]. Available: http://www.forewind.co.uk/zone-development/zone-developmentoverview.html. [Accessed: 20-Jul-2012].

[10] B. Jacobson, P. Karlsson, G. Asplund, L. Harnefors, and J. Tomas, "VSC-HVDC Transmission with Cascaded Two-Level Converters," Ludvika, Sweden, 2010.

[11] C. Feltes, H. Wrede, F. W. Koch, and I. Erlich, "Enhanced Fault Ride-Through Method for Wind Farms Connected to the Grid Through VSC-Based HVDC Transmission," IEEE Transactions on Power Systems, vol. 24, no. 3, pp. 1537-1546, 2009.

G. Ramtharan, A. Arulampalam, J. B. Ekanayake, F. M. Hughes, and N. Jenkins, "Fault ride through of fully rated converter wind turbines with $\mathrm{AC}$ and DC transmission systems," IET Renewable Power Generation, vol. 3, no. 4, pp. 426-438, 2009.

[13] J. J. Grainger and W. D. Stevenson, Power system analysis. McGraw-Hill, 1994, p. 787.

[14] R. Majumder, B. Chaudhuri, A. Ghosh, R. Majumder, G. Ledwich, and F. Zare, "Improvement of Stability and Load Sharing in an Autonomous Microgrid Using Supplementary Droop Control Loop," IEEE Transactions on Power Systems, vol. 25, no. 2, pp. 796-808, May 2010.

Jonathan M. Stevens (S'12) received the B.Eng degree in electrical and electronic engineering from the School of Engineering, Cardiff University, Cardiff, UK, in 2011 and is currently pursuing the Ph.D degree in Electrical Engineering within the Institute of Energy, Cardiff University, Cardiff, UK.

His research interests include offshore HVDC transmission systems, flexible ac transmission systems, power electronics and renewable generation control.

Daniel J. Rogers (M’09) received the M.Eng. and Ph.D. degrees in electrical and electronic engineering from Imperial College London, London, U.K., in 2007 and 2011 respectively. Currently, he is a Lecturer in the Institute of Energy, Cardiff University, Cardiff, U.K. He conducts research in collaboration with industry and is involved with the development of highperformance power electronic systems for a variety of companies. He is a coinvestigator on the multi-institution EPSRC Energy Storage for Low Carbon Grids project. His interests include the use of medium- and large-scale power-electronic systems to create flexible electrical networks capable of taking advantage of a diverse range of generation technologies, and the subsequent control challenges this produces. 